\title{
Cognitive mechanisms underlying Armoni: A computer-assisted cognitive training programme for individuals with intellectual disabilities
}

\author{
Claudia Peñaloza ${ }^{1}$, José Gutiérrez-Maldonado ${ }^{1 *}$, Marta Ferrer-García ${ }^{1}$, Alejandra Caqueo-Urízar ${ }^{2}$, Antonio Reverter- \\ Guimeso $^{3}$, Yolanda Macías-Cajal ${ }^{3}$, David Amela-Huemes ${ }^{3}$, and Sandra Perales-Josa ${ }^{3}$
}

\author{
1Department of Personality, Assessment and Psychological Treatments. Universitat de Barcelona (Spain). \\ 2Department of Philosophy and Psychology. Universidad de Tarapacá (Chile). \\ 3Fundació Ave Maria, Barcelona (Spain).
}

\begin{abstract}
Título: Mecanismos cognitivos que subyacen a Armoni: Un programa de entrenamiento cognitivo asistido por ordenador para personas con discapacidades intelectuales.

Resumen: Aunque se han descrito varios déficits cognitivos en individuos con discapacidades intelectuales (DI), pocos estudios han examinado el uso de programas de entrenamiento cognitivo asistidos por ordenador en este grupo de personas. Este estudio trata de determinar los mecanismos cognitivos subyacentes a 16 actividades incluidas en Armoni, un programa de en trenamiento cognitivo computarizado para individuos con DI, con el fin de validar su uso en esta población. Cincuenta adultos con DI de cuatro centros de atención residencial en España fueron sometidos a pruebas neuropsicológicas de tapping atencional, memoria verbal, memoria visual, comprensión, visuopercepción, visuoconstructión, capacidad de nombrar, fluidez verbal, razonamiento verbal y función motora. Además, se llevaron a cabo las 16 actividades incluidas en el programa de Armoni. Las relaciones entre la función cognitiva y las actividades basadas en el ordenador se evaluaron utilizando correlaciones de Spearman. Después se utilizó análisis de regresión múltiple por pasos para explorar cómo la función cognitiva predice el rendimiento de las personas con DI en las actividades del programa. La mayoría de las actividades del programa correlacionaron con visuoconstructión, comprensión y capacidad de nombrar. La capacidad de nombrar, la memoria visual, la comprensión y la visuoconstructión fueron las que más contribuyeron en los modelos predictivos sobre el desempeño en las actividades de Armoni. Nuestros resultados apoyan la validez de Armoni para el entrenamiento cognitivo en las personas con DI.

Palabras clave: Discapacidades intelectuales; funciones cognitivas; entrenamiento cognitivo; Armoni; asistido por ordenador
\end{abstract}

\section{Introduction}

Intellectual disability (ID) is a severe chronic condition involving a wide variety of difficulties and limitations of varying degrees of severity which lead to some degree of functional impairment and a lifelong need for support and intervention (Taylor, Lindsay, \& Willner, 2008). These difficulties include deficits in cognitive functioning and adaptive behaviour (Tremblay, Richer, Lachance, \& Côté, 2010).

Cognitive deficits in people with ID of different specific aetiologies have been reported in almost every aspect of cognition (Su, Lin, Wu, \& Chen, 2008). These deficits affect visual search (Cha \& Merrill, 1994), verbal short-term memory (Purser \& Jarrold, 2005) working memory (Hartman, Houwen, Scherder, \& Visscher, 2010; Silverman, 2007), long-term memory (Carlesimo, Marotta, \& Vicari, 1997), language (Contestabile, Benfenati, \& Gasparini, 2010), visuoconstruction and visuospatial skills (Vicari, Bellucci,

* Dirección para correspondencia [Correspondence address]:

José Gutiérrez-Maldonado. Department of Personality, Assessment and Psychological Treatments. Universitat de Barcelona. Passeig de la Vall d'Hebron, 171. CP 08035. Barcelona (Spain).

E-mail: igutierrezm@ub.edu
Abstract: Although a number of cognitive deficits have been described in individuals with intellectual disabilities (ID), few studies have examined the use of computer-assisted cognitive training programmes in this group of people. This study sought to determine the cognitive mechanisms underlying 16 activities included in Armoni, a computerized cognitive training programme for individuals with ID, in order to validate its use with this population. Fifty adults with ID from four residential care centres in Spain underwent neuropsychological testing tapping attention, verbal memory, visual memory, comprehension, visuoperception, visuoconstruction, naming ability, verbal fluency, verbal reasoning and motor function. In addition, they performed 16 activities included in the Armoni programme. The relationships between cognitive function and the computer-based activities were assessed using Spearman correlations. Stepwise multiple regression analyses were then used to explore how cognitive function predicted the performance of individuals with ID on the programme activities. Most programme activities correlated with visuoconstruction, comprehension and naming ability. Naming ability, visual memory, comprehension and visuoconstruction contributed the most to the predictive models regarding performance on the Armoni activities. Our findings support the validity of Armoni for cognitive training in individuals with ID.

Key words: Intellectual disabilities; cognitive functions; cognitive training; Armoni; computer-assisted.

Carlesimo, 2006), executive functions (Rowe, Lavender, \& Turk, 2006) and motor skills (Hartman et al., 2010; Vicari, 2006).

Cognitive training involves guided practice on a range of standard tasks related to one or more cognitive domains (Halligan \& Wade, 2005). One of the main methods used in this context is computer-assisted training (Reynolds \& Fletcher-Janzen, 2007). Although a range of application software has been developed to train basic adaptive skills for daily living in people with ID (Ayres \& Cihak, 2010; Davis, Stock, \& Wehmeyer, 2003; Mechling, Gast, \& Langone, 2002; Taber, 2003), few studies have focused on the development of computer-based programmes for cognitive training in this population. Research in this field has mainly focused on specific cognitive abilities such as metacognition (Moreno \& Saldaña, 2005), decision making (Standen, Rees, \& Brown, 2009) or working memory (Van der Molen et al., 2010), leaving the training of multiple cognitive domains scarcely addressed. Although the literature illustrates the potential of computer-based cognitive training programmes, the evidence supporting its use in the field of ID is only recent and further research is clearly required. 
Armoni is a computer-based programme that has been developed to train a variety of cognitive functions in individuals with ID. The present study had two aims: first, to examine the cognitive functions underlying a subset of 16 activities included in Armoni, and second, to determine the extent to which the performance of individuals with ID on these activities can be predicted by their neuropsychological performance. Exploring the relationships between the Armoni activities and cognitive function at these two levels will allow the Armoni activities to be validated and will add to the current literature on the use of computerized programmes for training cognitive abilities in individuals with ID.

\section{Methods}

\section{Participants}

The initial sample consisted of 59 participants with ID recruited from four residential care centres in Catalonia, Spain: Fundació Ave María $(n=7)$, Centre d'Atenció Especialitzada (CAE) Marinada $(n=11)$, Tegar-Tallers Especials del Garraf $(n=19)$, and Fundació Privada Auria $(n=22)$. Inclusion criteria were: being aged 18 and over, and having an official diagnosis of ID upon admission to the residential centre. Participants were excluded if they had a coexisting diagnosis of severe mental disorder, severe neurological impairment, or severe sensory or motor deficit that interfered with testing.

Three participants ( $>60$ years) were excluded to minimize the potential effects of age and the possibility of dementia. A further three participants were excluded due to neurological conditions, including temporal lobe epilepsy, hemiplegia and hemiparesis. Two participants dropped out of the study because they were granted temporary permits to visit their families, and the data from one participant were excluded because an increasing rate of epileptic seizures interfered with his data collection. The final sample therefore comprised 50 participants.

The sample was $46 \%$ female and ranged in age from 19 to 56 years $(M=33.4 ; S D=10.5)$. According to the clinical records held by the residential centres, participants were diagnosed with mild $(26 \%)$, moderate $(36 \%)$ or severe $(26 \%)$ ID; the degree of ID in the remaining participants $(12 \%)$ was unreported. Aetiology of ID was heterogeneous and in many cases unknown.

\section{Measures}

Cognitive ability. All participants underwent a comprehensive battery of neuropsychological tests addressing a variety of cognitive domains. Attention and verbal reasoning were evaluated using, respectively, the Digit Span and Similarities subtests of the Wechsler Adult Intelligence Scale (WAIS-III; Wechsler, 1997a). Verbal memory and learning were assessed using the Word List I and Word List II sub- tests of the Wechsler Memory Scale (WMS-III; Wechsler, 1997b), with three aspects being considered: the score for immediate total recall across learning trials provided a measure of immediate verbal memory; the long-delay free recall score offered a measure of long-term verbal memory; and the recognition score was taken as a measure of verbal recognition. Visual memory was assessed with the Faces subtest of the Rivermead Behavioural Memory Test (RBMT; Wilson, Cockburn, \& Baddeley, 1985). Two subtests of the Integrated Program of Neuropsychological ExaminationRevised Barcelona Test (Peña-Casanova, 2005), namely Comprehension of Instructions and Visuoconstructive Drawing-Copy, were used to examine comprehension and visuoconstruction, respectively. Visuoperception was evaluated with the Benton Visual Form Discrimination Test (VFDT; Benton, Sivan, Hamsher, Varney, \& Spreen; 1994). Naming ability was measured with the Boston Naming Test (BNT; Kaplan, Goodglass, \& Weintraub, 2001). Verbal fluency was examined using the animal naming task of the Boston Diagnostic Aphasia Examination (BDAE; Goodglass \& Kaplan, 1983). Motor functioning was assessed with the Purdue Pegboard Test (Tiffin, 1968).

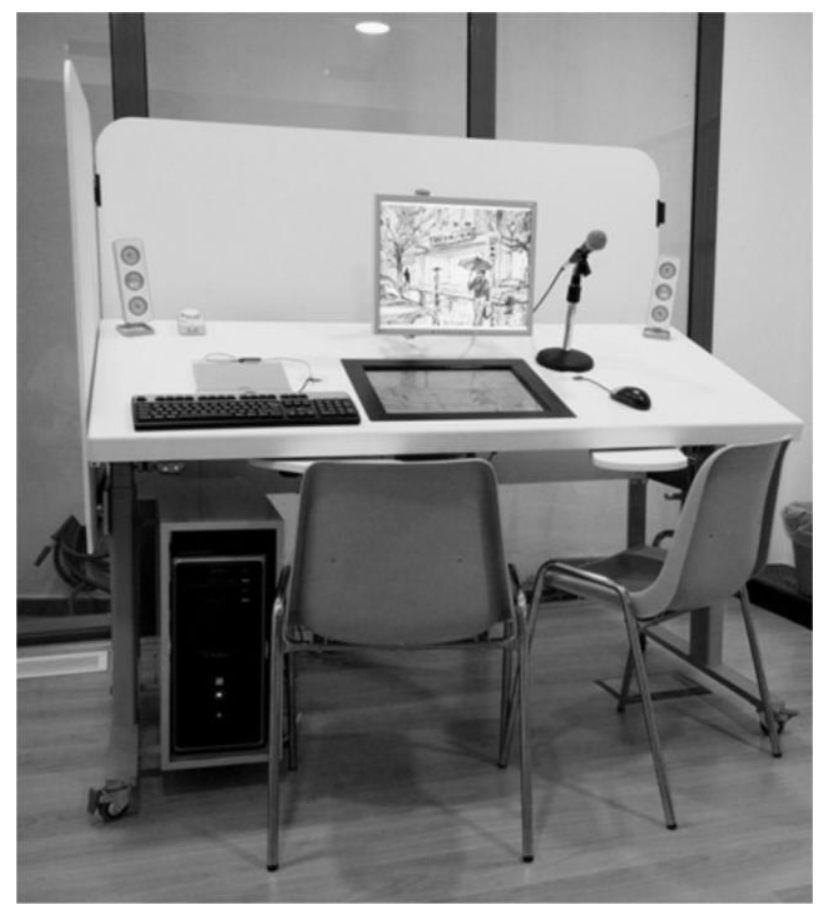

Figure 1. The Armoni work station.

Armoni activities. Armoni is a computer-assisted programme designed by the Fundació Ave María in Sitges (Spain) and the Institute of Biomechanics in Valencia (Spain) with the purpose of training cognitive functions in adults with ID. It consists of both application software and a work station designed to facilitate its use by individuals with ID. The system requirements for running the software are as follows: a Pentium III, or more advanced, processor; random 
access memory (RAM) of 256 megabytes (MB) or greater; a hard disc drive with 300 free MB; Microsoft Windows XP, Vista or Windows 7 (32 bit) operating system; a graphics card resolution of 1024 by 768 pixels; support for two monitors; and a compatible sound card (Figure 1). The software includes a variety of time-limited activities that provide visual stimuli and require motor performance on a touchscreen. Some activities also include auditory stimuli and require a second screen. Activity difficulty, stimuli content and stimuli properties are flexible and may be adjusted to the user's needs and limitations. The application provides the user with automatic visual and auditory feedback about task performance and the need for further attempts to achieve a given goal. The individual performance on each activity is expressed as a score on one or more outcome measures, including hits, errors, completion time and accuracy, all of which are automatically recorded on a Microsoft Office Excel spreadsheet. A subset of 16 of the 40 activities included in Armoni (hereinafter referred to as Armoni-UB) were considered for the present study. Table 1 provides a brief description of each Armoni-UB activity.

Table 1. Description of the Armoni-UB activities in order of administration and outcome scores showing maximum possible values.

\begin{tabular}{ll} 
Activity description & Outcome scores \\
\hline Dancing Image (DI) & Hits: undefined ${ }^{*}$
\end{tabular}

A basketball appears on the touchscreen several times during a fixed period of $60 \mathrm{~s}$. The activity requires Errors: undefined * the participant to touch the ball as quickly as possible whenever it appears on the screen.

Conveyor Band (CB) Hits: 6

The second screen displays the target stimulus (a chocolate cookie) for visual reference during the activity. Omission errors: undefined * The main screen shows a conveyor band that moves from left to right carrying chocolate cookies mixed Commission errors: undefined among apples, oranges and pears (foils). Stimuli are presented one by one in a fixed order. The goal is to *

touch the six chocolate cookies before they disappear from the screen. The sequence of stimuli is presented Accuracy: $100 \% *$ continuously until all target objects are selected.

Recognizing Objects (RO)

Completion time: 60 seconds *

A bike (target) is shown on the second screen for $5 \mathrm{~s}$ while the main screen shows four cards upside down. Errors: undefined

After the $5 \mathrm{~s}$ exposure the four cards are simultaneously uncovered for $10 \mathrm{~s}$, displaying the target stimulus Accuracy: $100 \%$ *

and three foils: an airplane, a car and a train. The goal is to identify the card with the target. After exposure Completion time: 60 seconds *

the four cards are covered and the participant must identify the card with the hidden target stimulus by touching it on the main screen.

Identifying Sounds (IS) Hits:4

A cat, a dog, a cow and a sheep appear on the main screen. One by one the sounds made by these animals Errors: undefined are reproduced and the participant has to identify the animal associated with each sound by touching its Accuracy: $100 \%$ * image on the screen. After each correct association the next sound is reproduced and the image of the ani- Completion time: 60 seconds * mal previously selected becomes unavailable for further selection.

Object Matrix-I (OM-I) Hits:4

Four images of human body parts (two feet, a hand, an eye and a mouth) are displayed in a row at the top Errors: undefined *

of the main screen, each one displaying a blank square below. Four images (a pair of gloves, a glass of wa- Accuracy: 100\% *

ter, a pair of shoes and a pair of glasses) are displayed at the bottom. The goal is to match the images of the Completion time: 60 seconds * second set with those of the first, moving them to the blank squares.

Labyrinth (L) Hits: 1

A narrow path that begins in the lower left corner and ends in the upper right corner is displayed on the Errors: undefined * main screen. A token (the image of an apple) is shown both at the beginning and end of the path. Partici- Accuracy: $100 \%$ *

pants must move the token from left to right along the path until the two images overlap. Touching the Completion time: 60 seconds * boundaries of the path while moving the token is penalized and computed as an error.

Target Shooting (TS) Hits: 6

The main screen shows six small cakes that move in different directions in a random pattern. The activity Errors: undefined *

requires the participant to touch the cakes as quickly as possible. Cakes disappear from the screen when hit. Completion time: 60 seconds * Fit the Image (FI) Hits: 1

The main screen shows the image of a car in the upper part and three images below: an apple, two yogurt Errors: undefined

pots and a car. Participants must select the image that best matches the target stimulus. The image selected Completion time: 60 seconds * must be moved to the target stimulus area so that the two are superimposed.

Find the Difference (FD) Hits: 1

A colourful ball is displayed in full size on the second screen. The main screen shows the same ball but Errors: undefined

smaller and superimposed on a collage of soccer balls and basketballs. Participants must identify the target Accuracy: $100 \%$ *

ball among the other balls by touching it on the main screen as quickly as possible. Completion time: 60 seconds *

Oral Comprehension (OC) Hits: 8 *

Eight series of varying stimuli are presented on the main screen. Participants must identify and select one Errors: undefined *

object among others on verbal request. Elements shown must be identified according to quantity, size and Accuracy: $100 \%$ *

shape, characteristics such as empty/full or open/closed, and concepts such as number, letter and colour. Completion time: 90 seconds * Distractors are one or two objects of the same category. Each series is presented after completion of the

previous one. 


\begin{tabular}{|c|c|}
\hline Activity description & Outcome scores \\
\hline It's Raining Objects (IRO) & Hits: 5 \\
\hline $\begin{array}{l}\text { The second screen displays the target stimulus (a yellow toy duck). On the main screen two types of objects } \\
\text { are shown: the yellow toy duck and a foil (a red surprise box). Four or five objects appear at a time in a } \\
\text { fixed sequence, moving downwards, as if they were falling from top to bottom. The activity requires the } \\
\text { participant to touch the five ducks before they disappear from the screen. The sequence of objects is con- } \\
\text { tinuously presented until all targets are selected. The second screen continues to display the target stimulus } \\
\text { for visual reference during the activity. }\end{array}$ & $\begin{array}{l}\text { s Omission errors: undefined }{ }^{*} \\
\text { a Commission errors: undefined } \\
\text { e }^{*} \\
\text { - Accuracy: } 100 \%{ }^{*} \\
\text { s Completion time: } 60 \text { seconds * }\end{array}$ \\
\hline Ordering Sequences (OS) & Hits: 3 \\
\hline $\begin{array}{l}\text { A row of three blank squares is shown at the top of the main screen. Three images are displayed at the bot- } \\
\text { tom showing three basic steps for washing one's hands, although not presented in the correct sequence. }\end{array}$ & \\
\hline $\begin{array}{l}\text { Images consist of two dirty hands, a man drying his hands with a towel, and a man washing his hands. Par- } \\
\text { ticipants must organize the images in the correct sequence by selecting the images in the correct order and } \\
\text { moving them into the blank boxes at the top of the screen. }\end{array}$ & \\
\hline Follow the Trace (FT) & Hits: $100 \%{ }^{*}$ \\
\hline $\begin{array}{l}\text { The image of a car with its contour outlined in red is displayed on the main screen. Participants must care- } \\
\text { fully draw a yellow line on top of the red line, without colouring other areas of the image. }\end{array}$ & $\begin{array}{l}\text { - Errors: undefined }{ }^{*} \\
\text { Completion time: } 60 \text { seconds }\end{array}$ \\
\hline Object Matrix-II (OM-II) & Hits: 3 \\
\hline $\begin{array}{l}\text { A } 2 \times 3 \text { matrix is shown on the main screen. The first column displays three T-shirts in pink, brown and yel- } \\
\text { low, while the second column shows blank squares located to the right of the T-shirt images. The bottom } \\
\text { of the screen displays a row of three plastic clothespins in the same colours. Participants must select the } \\
\text { clothespin that matches the colour of each T-shirt, moving them to the empty boxes located to the right of } \\
\text { each T-shirt. }\end{array}$ & $\begin{array}{l}\text { - Errors: undefined }{ }^{*} \\
\text { Accuracy: } 100 \%{ }^{*} \\
\text { Completion time: } 60 \text { second } \\
\end{array}$ \\
\hline Purzle (PU) & Hits: $6^{*}$ \\
\hline $\begin{array}{l}\text { The second screen displays the image of a cow. The main screen shows an empty matrix composed of } \\
\text { three columns and two rows of blank boxes wherein the puzzle is to be assembled. A board with six puzzle } \\
\text { pieces is shown at the bottom of the main screen. Participants must assemble the puzzle by moving the } \\
\text { pieces from the board onto the empty matrix. The second screen continues to display the model for visual } \\
\text { reference during the activity. }\end{array}$ & $\begin{array}{l}\text { Errors: undefined }{ }^{*} \\
\text { Accuracy: } 100 \%^{*} \\
\text { Completion time: } 90 \text { seconds }\end{array}$ \\
\hline
\end{tabular}

\section{reference during he activity.}

Fine Motor Skills (FMS)
The main screen displays a bike on a vertical path that resembles a street with curves. The path moves con-

tinuously from top to bottom simulating a street view when a bike is pedalled upwards. Participants must keep their index finger pressed on the bike token and move it upwards along the path, being careful not to hit the curves. Touching the path boundaries while moving the bike token is penalized and computed as an error.

${ }^{*}$ Outcome scores included in the correlation analyses.

\section{Procedure}

The study was conducted at the four residential care centres. A pilot study with seven participants was conducted to identify the most suitable parameters of stimuli presentation and outcome measures for each activity, as well as to select the neuropsychological tests that best captured a range of scores and minimized the possibility of floor effects.

The procedure was fully explained to each participant, all of whom underwent a two-hour session involving two computerized activities not included in the study so as to become familiar with the touchscreen. Next, they performed the Armoni-UB activities in two sessions lasting one hour each. A training task preceded the administration of each activity. Activities were administered only after completion of the preceding training task, when it was determined that the participant could understand the basic task requirements. Participants were given the task instructions and were encouraged to complete the activity. Cognitive testing was conducted in two sessions, with the original test instructions being slightly modified to facilitate comprehension. Participants were allowed short breaks when they seemed tired or distracted. All procedures were approved by the Ethics Committee of the University of Barcelona and the clinical staff of the participating institutions. Both the clinical staff and the institutions' board members gave their informed consent.

\section{Statistical Analysis}

All analyses were conducted with SPSS Statistics 17.0. Because the measurement of cognitive abilities using conventional normative data is inappropriate for persons with ID due to substantial floor effects (Palmer, 2006; Edgin et al., 2010), only the direct scores on the neuropsychological tests and the outcome scores of the activities were considered for statistical analyses.

Given that the Kolmogorov-Smirnov test suggested a non-normal distribution for the outcome scores of ArmoniUB activities, Spearman rank-order correlations were used to examine the relationship between each outcome score on the computer-assisted activities and the direct scores on the neuropsychological tests. Because of the high number of correlations obtained in this analysis the probability level for 
significance was set at $p<.01$. Stepwise multiple regression analyses were then used to explore the extent to which the neuropsychological measures of participants could predict their performance on Armoni-UB activities, with the level of significance again being set at $p<.01$.

\section{Results}

\section{Correlations Between Armoni-UB Activities and Cognitive Functions}

Significant correlations were found between 15 ArmoniUB activities and 11 cognitive domains. Most of these activities showed a significant correlation with visuoconstruction, comprehension and naming ability, and presented a varying number of significant relationships with the remaining cognitive domains (Table 2).

\section{Regression Analyses}

Given that many activities were significantly correlated with more than one cognitive domain across different outcome scores, stepwise multiple regression analyses were used to determine which cognitive domains could best predict scores on Armoni-UB activities. More than one predictive model was identified for different measures of performance on three activities: Oral Comprehension, Conveyor Band and It's Raining Objects, with naming ability, visual memory, comprehension and visuoconstruction contributing the most to the predictive capacity of these models. The remaining activities were predicted by a single cognitive domain, although only to a moderate extent (Table 3).

Table 2. Spearman correlations between outcome scores on the Armoni-UB activities and the cognitive domains of interest.

\begin{tabular}{|c|c|c|c|c|c|c|c|c|c|c|c|c|}
\hline \multirow[t]{2}{*}{ Activities } & \multirow[t]{2}{*}{ Outcome scores } & \multicolumn{11}{|c|}{ Cognitive domains } \\
\hline & & IVM & LTM & VR & VM & $\mathrm{VP}$ & $\mathrm{A}$ & $\mathrm{VC}$ & MF & NA & $\mathrm{C}$ & $\mathrm{VF}$ \\
\hline DI & Hits & & & $\begin{array}{c}.368 \\
N=49\end{array}$ & & & & & & & $\begin{array}{c}.478 \\
N=48\end{array}$ & \\
\hline & Errors & & & & & $\begin{array}{c}-.509 \\
N=48\end{array}$ & & & & $\begin{array}{l}-.368 \\
N=49\end{array}$ & & \\
\hline $\mathrm{CB}$ & $\begin{array}{l}\text { Commission } \\
\text { Errors }\end{array}$ & & & & $\begin{array}{l}-.381 \\
N=49\end{array}$ & $\begin{array}{l}-.474 \\
N=49\end{array}$ & & $\begin{array}{l}-.480 \\
N=50\end{array}$ & & $\begin{array}{l}-.368 \\
N=50\end{array}$ & & \\
\hline & Accuracy & & & & & $\begin{array}{c}.443 \\
N=49 \\
\end{array}$ & & $\begin{array}{c}.435 \\
N=50 \\
\end{array}$ & & $\begin{array}{c}.434 \\
N=50 \\
\end{array}$ & $\begin{array}{c}.427 \\
N=49 \\
\end{array}$ & \\
\hline & Time & $\begin{array}{l}-.534 \\
N=48\end{array}$ & $\begin{array}{l}-.436 \\
N=48\end{array}$ & $\begin{array}{l}-.561 \\
N=48\end{array}$ & $\begin{array}{l}-.410 \\
N=47\end{array}$ & $\begin{array}{l}-.373 \\
N=47 \\
\end{array}$ & $\begin{array}{l}-.412 \\
N=48\end{array}$ & & & $\begin{array}{l}-.414 \\
N=48\end{array}$ & $\begin{array}{l}-.457 \\
N=47\end{array}$ & $\begin{array}{l}-.486 \\
N=47\end{array}$ \\
\hline $\mathrm{RO}$ & Accuracy & $\begin{array}{c}.471 \\
N=49\end{array}$ & $\begin{array}{c}.438 \\
N=49\end{array}$ & & & & & $\begin{array}{c}.551 \\
N=49\end{array}$ & & $\begin{array}{c}.544 \\
N=49\end{array}$ & $\begin{array}{c}.403 \\
N=48\end{array}$ & $\begin{array}{c}.345 \\
N=48\end{array}$ \\
\hline & Time & & & $\begin{array}{l}-.463 \\
N=46\end{array}$ & & & & & & & $\begin{array}{l}-.453 \\
N=38 \\
\end{array}$ & \\
\hline$\overline{\mathrm{IS}}$ & Accuracy & $\begin{array}{c}.407 \\
N=48\end{array}$ & $\begin{array}{c}.393 \\
N=48\end{array}$ & & & $\begin{array}{c}.384 \\
N=47\end{array}$ & & $\begin{array}{c}.371 \\
N=48\end{array}$ & & $\begin{array}{c}.449 \\
N=48\end{array}$ & & \\
\hline & Time & $\begin{array}{l}-.596 \\
N=41\end{array}$ & $\begin{array}{l}-.585 \\
N=41\end{array}$ & $\begin{array}{l}-.467 \\
N=41\end{array}$ & & & & & & $\begin{array}{l}-.449 \\
N=41\end{array}$ & & \\
\hline $\mathrm{L}$ & Errors & & & & & & & $\begin{array}{l}-.387 \\
N=50\end{array}$ & & & & \\
\hline & Accuracy & & & & & & & $\begin{array}{c}.451 \\
N=50 \\
\end{array}$ & & & $\begin{array}{c}.442 \\
N=49 \\
\end{array}$ & \\
\hline TS & Time & & & & & $\begin{array}{l}-.378 \\
N=49\end{array}$ & & & & & $\begin{array}{l}-.489 \\
N=49\end{array}$ & \\
\hline FI & Time & $\begin{array}{l}-.401 \\
N=47\end{array}$ & & & & & & & & & $\begin{array}{l}-.403 \\
N=46\end{array}$ & \\
\hline FD & Accuracy & & & & $\begin{array}{c}.546 \\
N=45\end{array}$ & $\begin{array}{c}.388 \\
N=44\end{array}$ & & $\begin{array}{c}.464 \\
N=45\end{array}$ & & $\begin{array}{c}.393 \\
N=45\end{array}$ & $\begin{array}{c}.491 \\
N=45\end{array}$ & \\
\hline & Time & & & & & & & $\begin{array}{l}.463 \\
N=43 \\
\end{array}$ & & $\begin{array}{l}.401 \\
N=43\end{array}$ & $\begin{array}{l}-.414 \\
N=43 \\
\end{array}$ & \\
\hline$\overline{\mathrm{OC}}$ & Hits & $\begin{array}{c}.529 \\
N=49\end{array}$ & & & $\begin{array}{c}.496 \\
N=48\end{array}$ & $\begin{array}{c}.373 \\
N=48\end{array}$ & & $\begin{array}{c}.478 \\
N=49\end{array}$ & $\begin{array}{c}.409 \\
N=4 \\
9\end{array}$ & $\begin{array}{c}.466 \\
N=49\end{array}$ & $\begin{array}{c}.497 \\
N=48\end{array}$ & $\begin{array}{c}.474 \\
N=48\end{array}$ \\
\hline & Errors & $\begin{array}{l}-.595 \\
N=49\end{array}$ & $\begin{array}{l}-.422 \\
N=49\end{array}$ & $\begin{array}{l}-.546 \\
N=49\end{array}$ & $\begin{array}{l}-.465 \\
N=48\end{array}$ & & $\begin{array}{l}-.548 \\
N=49\end{array}$ & $\begin{array}{l}-.671 \\
N=49\end{array}$ & $\begin{array}{c}-.504 \\
N=4 \\
9\end{array}$ & $\begin{array}{l}-.668 \\
N=49\end{array}$ & $\begin{array}{l}-.693 \\
N=48\end{array}$ & $\begin{array}{l}-.528 \\
N=48\end{array}$ \\
\hline & Accuracy & $\begin{array}{c}.639 \\
N=49\end{array}$ & $\begin{array}{c}.447 \\
N=49\end{array}$ & $\begin{array}{c}.552 \\
N=49\end{array}$ & $\begin{array}{c}.491 \\
N=48\end{array}$ & $\begin{array}{c}.385 \\
N=48\end{array}$ & $\begin{array}{c}.461 \\
N=49\end{array}$ & $\begin{array}{c}.688 \\
N=49\end{array}$ & $\begin{array}{c}.546 \\
N=4 \\
9\end{array}$ & $\begin{array}{c}.709 \\
N=49\end{array}$ & $\begin{array}{c}.714 \\
N=48\end{array}$ & $\begin{array}{c}.565 \\
N=48\end{array}$ \\
\hline
\end{tabular}




\begin{tabular}{|c|c|c|c|c|c|c|c|c|c|c|c|c|}
\hline \multirow[t]{2}{*}{ Activities } & \multirow[t]{2}{*}{ Outcome scores } & \multicolumn{11}{|c|}{ Cognitive domains } \\
\hline & & IVM & LTM & VR & VM & $\mathrm{VP}$ & A & $\mathrm{VC}$ & MF & NA & $\mathrm{C}$ & $\mathrm{VF}$ \\
\hline & Time & -.454 & & -.584 & & & & & & & -.693 & \\
\hline & & $N=33$ & & $N=33$ & & & & & & & $N=33$ & \\
\hline \multirow[t]{8}{*}{$\overline{\mathrm{IRO}}$} & Omission & -.432 & & & & & & -.565 & & -.415 & & \\
\hline & Errors & $N=42$ & & & & & & $N=42$ & & $N=42$ & & \\
\hline & Commission & & & -.421 & -.438 & & & -.543 & & & & \\
\hline & errors & & & $N=42$ & $N=42$ & & & $N=42$ & & & & \\
\hline & Accuracy & & & & & & & .567 & & & & \\
\hline & & & & & & & & $N=42$ & & & & \\
\hline & Time & & & & & & & -.424 & & & & \\
\hline & & & & & & & & $N=42$ & & & & \\
\hline \multirow[t]{4}{*}{$\overline{\mathrm{OS}}$} & Accuracy & & & .387 & & & & & & & & \\
\hline & & & & $N=46$ & & & & & & & & \\
\hline & Time & & & & & & & -.430 & & & & \\
\hline & & & & & & & & $N=35$ & & & & \\
\hline \multirow[t]{5}{*}{$\overline{\mathrm{FT}}$} & Hits & & & & & & & .468 & .498 & & .530 & \\
\hline & & & & & & & & $N=40$ & $N=4$ & & $N=40$ & \\
\hline & & & & & & & & & 0 & & & \\
\hline & Errors & & & & & -.451 & & & & & & \\
\hline & & & & & & $N=39$ & & & & & & \\
\hline \multirow[t]{9}{*}{$\overline{\mathrm{OM}-\mathrm{II}}$} & Errors & & & & & & & -.395 & -.389 & -.415 & -.431 & \\
\hline & & & & & & & & $N=45$ & $N=4$ & $N=45$ & $N=45$ & \\
\hline & & & & & & & & & 5 & & & \\
\hline & Accuracy & & & & & & & .388 & .393 & .414 & .444 & \\
\hline & & & & & & & & $N=45$ & $N=4$ & $N=45$ & $N=45$ & \\
\hline & & & & & & & & & 5 & & & \\
\hline & Time & & & & & & & & -.399 & & & \\
\hline & & & & & & & & & $N=4$ & & & \\
\hline & & & & & & & & & 1 & & & \\
\hline \multirow[t]{8}{*}{$\overline{\mathrm{PU}}$} & Hits & & & & & .485 & & .386 & & .401 & & \\
\hline & & & & & & $N=46$ & & $N=46$ & & $N=46$ & & \\
\hline & Errors & & & & & -.496 & & -.532 & & & & \\
\hline & & & & & & $N=46$ & & $N=46$ & & & & \\
\hline & Accuracy & & & & & .532 & & .559 & & .409 & & \\
\hline & & & & & & $N=46$ & & $N=46$ & & $N=46$ & & \\
\hline & Time & & & & & & & -.491 & & & & \\
\hline & & & & & & & & $N=31$ & & & & \\
\hline \multirow[t]{2}{*}{ FMS } & Errors & -.439 & -.400 & & & & & -.464 & & & -.395 & \\
\hline & & $N=49$ & $N=49$ & & & & & $N=49$ & & & $N=48$ & \\
\hline
\end{tabular}

Note: All correlations are significant at $p<.001$ (2 tailed).

Armoni activities: DI = Dancing Image, $\mathrm{CB}=$ Conveyor Band, RO = Recognizing Objects, IS $=$ Identifying Sounds, $\mathrm{L}=\mathrm{Labyrinth}, \mathrm{TS}=\mathrm{Target}$ Shooting, $\mathrm{FI}=$ Fit in Image, FD = Find the Difference, $\mathrm{OC}=$ Oral Comprehension, $\mathrm{IRO}=$ It's Raining Objects, OS = Ordering Sequences, FT = Follow the Trace, OM-II = Object Matrix-II, PU = Puzzle, FMS = Fine Motor Skills.

Cognitive domains: IVM = immediate verbal memory, LTM = long-term memory, VR = verbal recognition, $\mathrm{VM}=$ visual memory, $\mathrm{VP}=$ visuoperception, $\mathrm{A}$

$=$ attention, $\mathrm{VC}=$ visuoconstruction, $\mathrm{MF}=$ motor function, $\mathrm{NA}=$ naming ability, $\mathrm{C}=$ comprehension, $\mathrm{VF}=$ verbal fluency.

Table 3. Cognitive domains identified by stepwise regression analyses as predictors of different outcome scores on the Armoni-UB activities.

\begin{tabular}{|c|c|c|c|c|c|c|c|c|}
\hline Armoni activity & Outcome score & Model & Predictors & $(\beta) \dagger$ & $\boldsymbol{R}$ & $R^{2}$ & $F$ & $P$ \\
\hline \multirow[t]{2}{*}{ Dancing Image } & Hits & 1 & Comprehension & & .482 & .232 & 13.890 & .001 \\
\hline & Errors & 1 & Visuoperception & & .433 & .188 & 10.644 & .002 \\
\hline \multirow[t]{4}{*}{ Conveyor Band } & Commission & 1 & Visuoperception & & .416 & .173 & 9.650 & .003 \\
\hline & Accuracy & 1 & Visuoperception & & .442 & .196 & 11.184 & .002 \\
\hline & Time & 1 & Long-term memory & & .403 & .162 & 8.528 & .005 \\
\hline & & $\overline{2}$ & $\begin{array}{l}\text { Long-term memory + } \\
\text { Visual memory }\end{array}$ & $\begin{array}{l}-.299 \\
-.294 \\
\end{array}$ & .488 & .238 & 6.715 & .003 \\
\hline \multirow[t]{2}{*}{ Recognizing Objects } & Accuracy & 1 & Visuoconstruction & & .505 & .255 & 15.765 & .000 \\
\hline & Time & 1 & Comprehension & & .380 & .144 & 7.756 & .008 \\
\hline \multirow[t]{2}{*}{ Identifying Sounds } & Accuracy & 1 & Naming ability & & .374 & .140 & 7.318 & .010 \\
\hline & Time & 1 & Immediate verbal memory & & .565 & .319 & 18.288 & .000 \\
\hline
\end{tabular}




\begin{tabular}{|c|c|c|c|c|c|c|c|c|}
\hline Armoni activity & Outcome score & Model & Predictors & $(\beta) \dagger$ & $\boldsymbol{R}$ & $R^{2}$ & $F$ & $P$ \\
\hline \multirow[t]{2}{*}{ Labyrinth } & Errors & 1 & Visuoconstruction & & .342 & .117 & 6.344 & .015 \\
\hline & Accuracy & 1 & Visuoconstruction & & .457 & .209 & 12.400 & .001 \\
\hline Target Shooting & Time & 1 & Comprehension & & .380 & .144 & 7.749 & .008 \\
\hline Fit in Image & Time & 1 & Comprehension & & .350 & .123 & 6.155 & .017 \\
\hline \multirow{2}{*}{ Find the Difference } & Accuracy & 1 & Visual memory & & .557 & .311 & 18.932 & .000 \\
\hline & Time & 1 & Visuoconstruction & & .358 & .128 & 6.031 & .018 \\
\hline \multirow[t]{8}{*}{ Oral Comprehension } & Hits & 1 & Visual memory & & .547 & .299 & 58.850 & .000 \\
\hline & & 2 & $\begin{array}{l}\text { Visual memory }+ \\
\text { Naming ability }\end{array}$ & $\begin{array}{l}.482 \\
.339\end{array}$ & .640 & .410 & 15.625 & .000 \\
\hline & Errors & 1 & Visual memory & & .549 & .301 & 19.835 & .000 \\
\hline & & 2 & $\begin{array}{l}\text { Visual memory }+ \\
\text { Naming ability }\end{array}$ & $\begin{array}{l}-.482 \\
-.350\end{array}$ & .647 & .419 & 16.227 & .000 \\
\hline & & 3 & $\begin{array}{l}\text { Comprehension }+ \\
\text { Visuoconstruction }+ \\
\text { Visual memory }\end{array}$ & $\begin{array}{l}.369 \\
.371 \\
.231\end{array}$ & .777 & .603 & 22.298 & .000 \\
\hline & & 4 & $\begin{array}{l}\text { Comprehension }+ \\
\text { Visuoconstruction }+ \\
\text { Visual memory }{ }^{+} \\
\text {Naming ability }\end{array}$ & $\begin{array}{l}.258 \\
.220 \\
.291 \\
.300\end{array}$ & .809 & .654 & 20.327 & .000 \\
\hline & Time & 1 & Comprehension & & .635 & .403 & 20.947 & .000 \\
\hline & & 2 & $\begin{array}{l}\text { Comprehension }+ \\
\text { Verbal recognition }\end{array}$ & $\begin{array}{l}-.427 \\
-.377\end{array}$ & .708 & .502 & 15.112 & .000 \\
\hline \multirow[t]{3}{*}{ It's Raining Objects } & Omission errors & 1 & Immediate verbal memory & & .439 & .193 & 9.542 & .004 \\
\hline & Commission errors & 1 & Visuoconstruction & & .531 & .282 & 15.715 & .000 \\
\hline & & 2 & $\begin{array}{l}\text { Visuoconstruction }+ \\
\text { Visual memory }\end{array}$ & $\begin{array}{l}-.382 \\
-.366\end{array}$ & .627 & .394 & 12.662 & .000 \\
\hline \multirow[t]{2}{*}{ Object Matrix-II } & Errors & 1 & Visuoconstruction & & .345 & .119 & 5.807 & .020 \\
\hline & Accuracy & 1 & Comprehension & & .459 & .210 & 11.454 & .002 \\
\hline \multirow[t]{4}{*}{ Puzzle } & Hits & 1 & Visuoperception & & .516 & .267 & 15.993 & .000 \\
\hline & Errors & 1 & Visuoperception & & .547 & .299 & 18.789 & .000 \\
\hline & Accuracy & 1 & Visuoperception & & .595 & .354 & 24.073 & .000 \\
\hline & Time & 1 & Visuoconstruction & & .484 & .235 & 8.889 & .006 \\
\hline Fine Motor Skills & Errors & 1 & Immediate verbal memory & & .406 & .165 & 9.060 & .004 \\
\hline
\end{tabular}

\section{Discussion}

This study aimed to examine the relationship between 16 activities that form part of the Armoni computer-assisted cognitive training programme and a variety of cognitive domains in a sample of 50 adults with ID. In addition, we explored the capability of the neuropsychological measures to predict performance on these cognitive training activities.

\section{Relationships Between Armoni-UB Activities and Cognitive Functions}

Fifteen of the 16 activities in the Armoni-UB programme were significantly associated with a variety of cognitive domains, as assessed with a series of neuropsychological tests. Most of the activities showed moderate to strong relationships with visuoconstruction, comprehension and naming ability.

Follow the Trace, Fine Motor Skills, Labyrinth and Puzzle were associated with visuoconstruction. Drawing and assembling are the two large classes of visuoconstructive activity and they require planning, spatial organization and motor control (Lezak, Howieson, \& Loring, 2004). Conveyor Band, Find the Difference, Identifying Sounds, Ordering Sequences, Object Matrix-II and, more strongly, Recognizing Objects, Oral Comprebension and It's Raining Objects were also associated with this cognitive ability. The execution of these tasks is thought to require correct visual perception of stimuli, an accurate motor response and an appropriate conception of spatial relationships, the basic components of visuoconstruction (Lezak et al., 2004).

Several activities were strongly associated with comprehension. Performance on the Comprehension of Instructions subtest depends on both the comprehension of verbal information and motor performance (Peña-Casanova, 2005). These two conditions are required to complete all the Armoni activities, but they are especially reflected in Oral Comprehension, which showed the strongest relationship with this cognitive domain.

Numerous significant relationships were found between several activities and naming ability. Perceptual analysis and semantic processing play an important role in naming ability (Mitrushina, Boone, Ramazi, \& D'Elia, 2005), and naming failures are associated with lexical and phonological access 
(Barresi et al., 2000; Evrard, 2002). The activities associated with naming ability require the appropriate selection of a specific stimulus from among others on verbal request and in different contexts. Choosing the right stimulus requires both knowledge and comprehension of object names, and, therefore, semantic and lexical access may be involved as a previous but necessary step for correct object selection.

Eight activities showed moderately to strongly significant relationships with visual perception. Perceptual functions involve awareness, recognition, discrimination, patterning and orientation (Lezak et al., 2004). The discrimination and recognition components of visuoperception may be best reflected by activities involving: object identification and selection while these objects are presented among distracting stimuli (i.e. Conveyor Band, Find the Difference and Oral Comprehension); object detection as the object appears and disappears at different points or while it moves around the touchscreen (i.e. Dancing Image and Target Shooting); and image selection associated with sound recognition (i.e. Identifying Sounds). Other activities such as Follow the Trace and Puzzle involve feature detection and contour recognition, which are involved in visual information processing and which enable shape and size discrimination, orientation and elementary spatial localization (Done \& Hajilou, 2005).

Three activities were associated with visual memory: Conveyor Band, It's Raining Objects and Find the Difference. Shortterm memory, defined as the temporal retention of information (Navalón Vila, Pérez Sánchez, \& López-García, 1997), may be crucial for correct performance on these activities as they involve a visual memory demand; in this context, holding in mind a target stimulus while comparing it with the response choices may help to identify targets among distractors in less time, resulting in fewer errors and higher accuracy. Oral Comprehension was also associated with visual memory. These results likely reflect the influence of semantic knowledge on the recognition of nameable objects in this activity.

Three activities were associated with verbal fluency. The relationship between Conveyor Band and Recognizing Objects and verbal fluency may rely on some of the cognitive mechanisms involved in word generation, namely attention, shortterm memory and response inhibition capacity (Mitrushina et al., 2005), which are necessary for the correct identification and selection of stimuli. Oral Comprehension was the activity most strongly correlated with verbal fluency. Word generation is not only associated with executive functioning but also depends on vocabulary storage, which is relevant since semantic fluency tests tend to load on verbal tests (i.e. Vocabulary, Digit Span and the BNT) (Mitrushina et al., 2005). The ability to correctly identify target items among distractors of the same category on request on eight consecutive turns of this activity may rely on access to long-term vocabulary storage. This argument finds support in the strong associations between this activity's outcome measures and naming ability, as previously discussed.
Surprisingly, attention was significantly associated with only two activities: Conveyor Band and Oral Comprehension. Attentional functions underlie all cognitive domains and are assumed to maintain their activity (Lezak et al., 2004). Accordingly, attentional functions may influence the ability to accurately select target stimuli from an array of possible choices and may contribute to reduced task execution time in different activities associated with a wide variety of cognitive domains.

Only three activities showed significant relationships with motor function. The results suggest that manual dexterity plays a role in executing Follow the Trace, where performance clearly depends on motor control, although it was Oral Comprehension and Object Matrix-II that showed the greatest sensitivity to motor function. It is reasonable to assume that manipulative dexterity and agility may significantly influence accuracy and error rates in these activities as they require a motor response on the tactile screen. However, the absence of significant relationships between motor function and other activities that apparently rely on motor dexterity may suggest that other cognitive components based on perceptual, conceptual or visuoconstructive processing are more essential for performance.

Short-term memory requires the immediate recall of recent or continuously repeated material (Junqué \& Barroso, 2009). Conveyor Band, It's Raining Objects, Identifying Sounds and Recognizing Objects involve the presentation of a target stimulus and information needed for goal accomplishment. Holding the target stimuli in short-term storage plays an important role in these activities. Fine Motor Skills was strongly associated with immediate verbal recall and seemed to be more verbally mediated, as the instructions guiding proper performance provide a larger amount of more complex information compared with other activities.

It is unsurprising that the activities associated with immediate recall were also associated with recognition memory, as these are two relevant aspects of verbal memory. One aspect engaged in recognition memory is the requirement to judge whether a stimulus has been perceived in a specific context (Baddeley \& Eysenck, 2009). Accordingly, if the visual target stimuli presented in Conveyor Band, It's Raining Objects and Recognizing Objects and the auditory target stimuli presented in Identifying Sounds are properly held in short-term storage, they will likely be recognized effectively in later stimuli presentations. Ordering Sequences was associated with recognition memory but not with immediate verbal recall. In this case, recognition may play a role in organizing actions in a logical sequence, where information from everyday life must be recognized in a set of images in order to correctly arrange the set of stimuli presented.

The relationship between five activities of the ArmoniUB programme and long-term recall remains unclear. All the activities required immediate performance and their duration was fixed at no longer than 60-90 seconds. Conversely, longterm memory is often defined as the ability to recall information after a 20 - or 30-minute period during which a dif- 
ferent, unrelated task has been performed (Junqué \& Barroso, 2009). The relationships between Armoni activities and long-term memory therefore require further investigation.

\section{Interpretation of Predictive Models}

A number of cognitive domains more clearly predicted the performance of individuals with ID on the activities included in the Armoni-UB programme. Oral Comprehension was initially associated with all the cognitive domains considered for this study across a variety of outcome scores. However, only visual memory and naming ability significantly predicted hits and errors on this activity, which corroborates the idea that access to semantic knowledge is crucial in recognizing nameable objects from among a set of possible choices within the same category. Moreover, naming ability was the strongest component in a model that predicted accuracy on this task. These findings indicate that high task performance depends not only on the ability to comprehend general instructions and specific information regarding the task goal but also on the basic perceptual and motor components of visuoconstruction, reflected in the two error types that can be produced in this activity. In addition, the completion time is mainly mediated by comprehension and recognition memory.

Interestingly, Conveyor Band and It's Raining Objects, two activities with similar designs, were not predicted by the same cognitive measures. Visual perception predicted commission errors and accuracy on Conveyor Band, suggesting that the perceptual component is the most important ability needed for correct execution, whereas completion time on this task was best predicted by visual memory and long-term recall. Accordingly, the ability to hold in mind the target stimulus initially presented while searching for it among a set of distractors is central for task completion in less time. Outcome scores on It's Raining Objects were predicted by other cognitive functions. Visuoconstruction seems to be required for fast and accurate performance of this task. Additionally, error-free execution is thought to rely on different aspects of memory: immediate memory would seem essential to avoid omitting target stimuli when rapidly presented among distractors, whereas visual memory aids in target visual recognition. It is possible that the differences between these two activities depend on stimuli presentation and difficulty. A one-by-one stimulus presentation from left to right on the screen in Conveyor Band may facilitate proper comparison of stimuli and correct target identification, which relies more on perceptual ability. By contrast, the presentation of three to four stimuli rapidly 'falling' together from top to bottom in It's Raining Objects may require a more skilled perceptual ability and a fast, accurate motor response to achieve error-free performance. The memory component was the common aspect underlying execution time in both activities.

A one-factor model predicted performance on the remaining activities. The analysis of these models indicates that comprehension is essential for correct execution in Follow the Trace, Dancing Image and Object Matrix-II, which are thought to require more verbal support to facilitate performance. In addition, comprehension may influence completion time in Recognizing Objects, Target Shooting and Fit the Image. Visuoconstruction was the only factor retained in models predicting 1) accuracy in Recognizing Objects and Labyrinth, 2) the number of errors in Object Matrix-II, and 3) completion time in Find the Difference, which suggests that perceptual, spatial and motor ability are central to achieving correct performance in less time. Visual perception was the factor that best predicted errors in Dancing Image, and also hits and accuracy in Puzzle, indicating that the perceptual contribution is more relevant in these activities. Naming ability predicted accuracy in Identifying Sounds, whereas completion time was predicted by immediate recall. This indicates that successful performance depends on holding in mind the auditory stimuli and on proper access to the semantic system. Errors on Fine Motor Skills were influenced by immediate recall, confirming that verbal memory for the instructions that guide performance is essential for error-free execution. Finally, accuracy in Find the Difference seems to depend mainly on visual short-term memory for later recognition.

Although the amount of variance explained by these one-factor models was rather modest they may offer an appropriate basis for constructing stronger and more accurate predictive models for addressing how these activities tap a variety of cognitive domains. It is important to note that the existence of non-normal distributions, due to very high or low scores and the reduced variability of scores on the programme activities, means that these are not ideal data for regression analyses. However, parametric statistical tests are claimed to be robust to violations of the normality assumption (Glass, Peckham, \& Sanders, 1972; Robson, 2002), and the use of this statistical method helped achieve a clearer overview of the cognitive mechanisms associated with the programme activities.

The results obtained should be regarded as exploratory and must be interpreted with caution, as the study considered a relatively small sample with little group representation across different severity levels. Future studies with larger samples will provide stronger support for the associations between cognitive functions and the Armoni-UB activities addressed in this study, and will enable researchers to identify the extent to which these associations are similar across different levels of ID. Further research is also required to determine the efficacy of these activities when included in cognitive training programmes for individuals with ID. Confirmation of their efficacy would extend the range of validated practices for use with this population.

\section{Conclusion}

Our findings suggest that the Armoni-UB activities are strongly associated with visuoconstruction, comprehension and naming ability and that they appear to tap different as- 
pects of visual perception, visual and verbal memory, verbal fluency, attention span and motor function in adults with ID. Although determining the effectiveness of the ArmoniUB programme in improving specific cognitive functions in this population was beyond the scope of this study, these initial findings provide support for its validity as a method of

\section{References}

Ayres, K., \& Cihak, D. (2010). Computer- and Video-Based Instruction of Food-Preparation Skills: Acquisition, Generalization, and Maintenance. Intellectual and Developmental Disabilities, 48,195-208.

Baddeley, A., \& Eysenck, M.W. (2009). Memory. New York: Psychology Press.

Barresi, B.A., Nicholas, M., Tabor Connor, L., Obler, L.K., \& Albert, M.L. (2000). Semantic Degradation and Lexical Access in Age-Related Naming Failures. Aging Neuropsychology and Cognition, 7, 169-178.

Benton, A.L., Sivan, A.B., Hamsher, K.D., Varney, N., \& Spreen, O. (1994). Visual Form Discrimination. Contributions to neuropsychological assessment. New York: Oxford University Press.

Carlesimo, G.A., Marotta, L., \& Vicari, S. (1997). Long-term memory in mental retardation: Evidence for a specific impairment in subjects with Down's syndrome. Neuropsychologia, 35, 71-79.

Cha, K.H., \& Merrill, E.C. (1994). Facilitation and inhibition effects in visual selective attention processes of individuals with and without mental retardation. American Journal of Mental Retardation, 98, 594-600.

Contestabile, A., Benfenati, F., \& Gasparini, L. (2010). Communication breaks-Down: From neurodevelopment defects to cognitive disabilities in Down syndrome. Progressive Neurobiology, 91,1-22.

Davis, D., Stock, S., \& Wehmeyer, M.L. (2003). Utilization of computer technology to facilitate money management by individuals with mental retardation. Education and Training in Developmental Disabilities, 38,106-112.

Done, D.J., \& Hajilou, B.B. (2005). Loss of high-level perceptual knowledge of object structure in DAT. Neuropsychologia, 43, 60-68.

Edgin, J., Mason, G., Allman, M., Capone, G., DeLeon, I., Maslen, C., et al. (2010). Development and validation of the Arizona Cognitive Test Battery for Down syndrome. Journal of Neurodevelopmental Disorders, 2, 149-164.

Evrard M. (2002). Ageing and Lexical Access to Common and Proper Names in Picture Naming. Brain and Language, 81, 174-179.

Glass, G., Peckham, P., \& Sanders, J. (1972). Consequences of Failure to Meet Assumptions Underlying the Fixed Effects Analyses of Variance and Covariance. Review of Educational Research, 42, 237-288.

Goodglass, H., \& Kaplan, E. (1983). The assessment of aphasia and related disorders. Philadelphia: Lea \& Febiger.

Halligan, P.W., \& Wade, D.T. (2005). Effectiveness of rebabilitation for cognitive deficits. Oxford: Oxford University Press.

Hartman, E., Houwen, S., Scherder, E., \& Visscher, C. (2010). On the relationship between motor performance and executive functioning in children with intellectual disabilities. Journal of Intellectual Disability Research, 54, 468-477.

Junqué, C., \& Barroso, J. (2009). Manual de Neuropsicología. Madrid: Editorial Síntesis, S.A.

Kaplan, E., Goodglass, H., \& Weintraub, S. (2001). Boston Naming Test. Philadelphia: Lippincott Williams \& Wilkins.

Lezak, M., Howieson, D.B., \& Loring, D.W. (2004). Neuropsychological Assessment. Oxford: Oxford University Press.

Mechling, L.C., Gast, D.L., \& Langone, J. (2002). Computer-Based Video Instruction to Teach Persons with Moderate Intellectual Disabilities to Read Grocery Aisle Signs and Locate Items. Journal of Special Education, 35, 224-240.

Mitrushina, M., Boone, K.B., Ramazi, J., \& D' Elia, L.F. (2005). Handbook of normative data for neuropsychological assessment. New York: Oxford University Press.

Moreno, J., \& Saldaña, D. (2005). Use of a computer-assisted program to improve metacognition in persons with severe intellectual disabilities. Research in Developmental Disabilities, 26, 341-357. cognitive training and highlight its potential to promote diverse areas of cognitive functioning in individuals with ID.

Acknowledgments.- This study was supported by the Fundació Ave Maria. The authors thank the participants and the clinical staff of the collaborating institutions: Fundació Ave María, Tegar-Tallers Especials del Garraf, Fundació Privada Auria and CAE Marinada.

Navalón Vila, C., Pérez Sánchez, M.A., \& López-García, J.J. (1997). Activación de información categorial en tareas de memoria de reconocimiento de dibujos. Anales de Psicología, 13, 77-83.

Palmer, G.A. (2006). Neuropsychological profiles of persons with mental retardation and dementia. Research in Developmental Disabilities, 27, 299308.

Peña-Casanova J. (2005). Integrated neuropsychological exploration programBarcelona test revised. Barcelona: Masson.

Purser, H.R.M., \& Jarrold, C. (2005). Impaired verbal short-term memory in Down syndrome reflects a capacity limitation rather than atypically rapid forgetting. Journal of Experimental Child Psychology, 91, 1-23.

Reynolds, C.R., \& Fletcher-Janzen, E. (2007). Encyclopedia of special education, a reference for the education of children, adolescents and adults with disabilities and other exceptional individuals. New Jersey: John wiley \& Sons.

Robson C. (2002). Real world research: a resource for social scientists and practitionerresearchers. Malden: Wiley-Blackwell.

Rowe, J., Lavender, A., \& Turk, V. (2006). Cognitive executive function in Down's syndrome. British Journal of Clinical Psychology, 45, 5-17.

Silverman W. (2007). Down Syndrome: cognitive phenotype. Mental Retardation and Developmental Disabilities Research Reviews, 13, 228-236.

Standen, P., Rees, F., \& Brown, D. (2009). Effect of playing computer games on decision making in people with intellectual disabilities. Journal of Assistive Technologies, 3, 4-12.

Su, C.Y., Lin, Y.H., Wu, Y.Y., \& Chen, C.C. (2008). The role of cognition and adaptive behavior in employment of people with mental retardation. Research in Developmental Disabilities, 29, 83-95.

Taber, T.A. (2003). Obtaining assistance when lost in the community using cell phones. Research and Practice for Persons with Severe Disabilities, 28, 105116.

Taylor, J.L., Lindsay, W.R., \& Willner, P. (2008). CBT for People with Intellectual Disabilities: Emerging Evidence, Cognitive Ability and IQ Effects. Behavioral and Cognitive Psychotherapy, 36, 723-733.

Tiffin J. (1968). Purdue Pegboard: Examiner manual. Chicago: Science research Associates.

Tremblay, K.N., Richer, L., Lachance, L., \& Côté, A. (2010). Psychopathological manifestations of children with intellectual disabilities according to their cognitive and adaptive behavior profile. Research in Developmental Disabilities, 31, 57-69.

Van der Molen, M.J., Van Luit, J.E.H., Van der Molen, M.W., Klugkist, I., \& Jongmans, M.J. (2010). Effectiveness of a computerised working memory training in adolescents with mild to borderline intellectual disabilities. Journal of Intellectual Disabilitiy Research, 54, 433-447.

Vicari S. (2006). Motor Development and Neuropsychological Patterns in Persons with Down Syndrome. Behavior Genetics, 36, 355-364.

Vicari, S., Bellucci, S., \& Carlesimo, G.A. (2006). Evidence from two genetic syndromes for the independence of spatial and visual working memory. Developmental Medicine and Child Neurology, 48, 126-131.

Wechsler, D. (1997a). Wechsler Adult Intelligence Scale-Third Edition (WAIS-III). San Antonio-Texas: The Psychological Corporation.

Wechsler, D. (1997b). Wechsler Memory Scale-Third Edition (WMS-III). San Antonio-Texas: The Psychological Corporation.

Wilson, B., Cockburn, K., \& Baddeley, A. (1985). The Rivermead Behavioural Memory Test (RBMT). Bury St. Edmunds: Thames Valley Test, Co.

(Article received: 12-03-2014; revised: 04-09-2014; accepted: 06-10-2014) 